\title{
O Dimensionamento de Pessoal como Fator de Humanização do Trabalho Enfermeiro em Unidade de Terapia Intensiva
}

\author{
Nicola, Anair Lazzari; Girardello, Débora T. Feiber; Fernandes, Luciana Magnani; \\ Casarolli, Ana Cristina Geiss; Barbosa, Halana Batistel; Paiano, Lara Adrianne \\ Garcia; Eberhardt, Thaís Dresch
}

Universidade Estadual do Oeste do Paraná — anairln@yahoo.com.br

Introdução: Garantir um quantitativo de profissionais enfermeiros qualificados e adequados para atender às demandas assistenciais em unidades de terapia intensiva (UTI) é um dever da instituição hospitalar, pois isso garante não somente qualidade e humanização na assistência, como também garante um ambiente de trabalho adequado ao profissional de enfermagem. Objetivos: Analisar as horas requeridas para assistência de enfermagem ao paciente crítico e as horas disponíveis do profissional enfermeiro em uma Unidade de Terapia Intensiva adulto e comparar com legislação vigente. Método: Estudo documental descritivo realizado em uma UTI de um hospital de ensino no Paraná. Foram calculadas as horas requeridas de enfermagem por meio do valor médio do índice nas (paciente/dia), foi também calculado a diferença entre as horas disponíveis de cuidados prestados pelo enfermeiro e as horas requeridas de cuidado privativo do enfermeiro usando como referência percentual de $52 \%$, de acordo com a legislação. o estudo foi aprovado no Comitê de Ética da Universidade Estadual do Oeste do Paraná pelo parecer ํㅜ 014/2011. Resultados: Foram coletados registros de 30 pacientes (210 escores NAS). o valor médio de horas requeridas de cuidado de enfermagem foi de 23,9 horas por paciente/dia $(99,6 \%$ no NAS) e analisando que apenas cinco enfermeiros estavam lotados na UTI no mês da pesquisa, representando uma média 2,8 enfermeiros/dia representando 16,8 horas de enfermeiro/dia para sete pacientes/dia. a média semanal de horas disponíveis de enfermeiros, da primeira à quinta semana, foi de 16,3 horas, 16,7 horas, 17,1 horas e 17,1 horas e 16 horas e a média de horas requeridas paciente/dia foi 88,4 horas, 87 horas, 86 horas, 85,8 horas e 87,1 horas o que determina um déficit entre os valores médios semanais de horas requeridas menos as médias semanais de horas disponíveis de enfermeiro foi de 57,6 horas, o que representa a carga horária de11,7 enfermeiros/dia. Conclusões: Os resultados evidenciaram um déficit importante de enfermeiros assistenciais o que demonstra que a instituição não atende às recomendações legais vigentes, nem ao direito do paciente crítico de ser atendido por profissionais com maior conhecimento técnico e científico, o que influencia na qualidade e segurança da assistência e na qualidade das condições de trabalho e de vida dos enfermeiros. a sobrecarga de trabalho, a falta de tempo, o número insuficiente de profissionais dificultam a realização do planejamento das ações ou intervenções de enfermagem, além disso, estudos apontam que os enfermeiros de setores como as UTI e as emergências são os profissionais mais acometidos por doenças causadas pelo estresse e baixa qualidade de vida pessoal e no trabalho, o que torna necessário garantir a correta adequação do número de profissionais enfermeiros o que consequentemente refletirá na diminuição da carga de trabalho e qualificando a assistência prestada.

Nicola, Anair Lazzari; Girardello, Débora T. Feiber; Fernandes, Luciana Magnani; Casarolli, Ana Cristina Geiss; Barbosa, Halana Batistel; Paiano, Lara Adrianne Garcia; Eberhardt, Thaís Dresch. O Dimensionamento de Pessoal como Fator de Humanização do Trabalho Enfermeiro em Unidade de Terapia Intensiva. In: Anais do Congresso Internacional de Humanidades \& Humanização em Saúde [= Blucher Medical Proceedings, num.2, vol.1]. São Paulo: Editora Blucher, 2014. ISSN 2357-7282

DOI 10.5151/medpro-cihhs-10526 